\begin{tabular}{|l|l|}
\hline Postprint Version & 1.0 \\
\hline Journal website & http://vb23.bsl.nl/BSL/content/nav/1388-7491/inh/inh.htm \\
\hline Pubmed link & \\
\hline DOI & \\
\hline
\end{tabular}

This is a NIVEL certified Post Print, more info at http://www.nivel.eu

\title{
Evaluatie van kansrijke beweegprogramma's om lichaamsbeweging in de Nederlandse bevolking te bevorderen
}

\author{
CHANTAL J. LEEMRIJSE ${ }^{1}$, LINDA OOMS ${ }^{1}$, CINDY VEENHOF ${ }^{1}$
}

${ }^{1}$ NIVEL - Nederlands Instituut voor onderzoek van de gezondheidszorg, Utrecht

In het kader van het Nationaal Actieplan Sport en Bewegen (NASB) worden 'bewegingsarme' gemeenten gesubsidieerd om programma's in te zetten teneinde de bevolking te stimuleren tot meer bewegen. Door het NIVEL is in samenwerking met NISB een inventarisatie gemaakt van beweegprogramma's en werden kwaliteitsaspecten van deze programma's in kaart gebracht. Via verschillende kanalen is gezocht naar beweegprogramma's. Programma-eigenaren werd gevraagd materiaal zoals handleidingen, stappenplannen, protocollen, onderzoeks- en voortgangsverslagen op te sturen. Aan de hand van dit materiaal en met behulp van een toetsingsformulier zijn de praktische uitvoerbaarheid van het programma, de theoretische en empirische onderbouwing en de ervaringen in de praktijk beoordeeld. Er werden 72 relevante beweegprogramma's gevonden en ingedeeld in vier categorieën die variëren in de mate van uitvoerbaarheid en onderbouwing. In de hoogste categorie zijn vijf programma's opgenomen waarvoor in gecontroleerd onderzoek positieve effecten op bewegen zijn aangetoond. Bij 33 programma's uit de laagste categorie is nog geen enkele effectmeting ten aanzien van 'meer bewegen' uitgevoerd. Algemeen kan worden gesteld dat er nog veel aandacht nodig is voor het onderbouwen van bestaande beweegprogramma's om de meer en minder effectieve programma's van elkaar te onderscheiden. In de toekomst zouden de meest kansrijke beweegprogramma's moeten worden ingezet.

\section{INLEIDING}

Nederlanders bewegen te weinig en te weinig intensief. Onvoldoende lichaamsbeweging gaat gepaard met gezondheidsrisico's. ${ }^{1}$ Om inactieve Nederlanders in beweging te krijgen heeft de rijksoverheid het Nationaal Actieplan Sport en Bewegen (NASB) in het leven geroepen. ${ }^{2}$ Het NASB wordt onder andere uitgevoerd door het Nederlands Instituut van Sport en Bewegen (NISB), het Nederlands kennis- en innovatie-instituut dat aanzet tot sport en bewegen om participatie, leefbaarheid en gezondheid te bevorderen. De Impuls NASB is een tijdelijke stimuleringsregeling van het ministerie van Volksgezondheid, Welzijn en Sport (VWS) die in 2008 in werking is getreden. In twee tranches van elk vier jaar worden 42 respectievelijk 50 'bewegingsarme' gemeenten in het kader van deze Impuls gedeeltelijk gesubsidieerd. De eerste tranche is eind 2008 gestart en loopt tot 2012, de tweede tranche startte in 2010 en eindigt in 2014. De subsidie is bedoeld om op gemeenteniveau beweegprogramma's te kunnen inzetten om de 'te weinig actieven' onder de bevolking te stimuleren tot meer bewegen. Het inzicht van gemeenten in het aanbod van interventies is echter beperkt. ${ }^{3}$ Om gemeenten te ondersteunen in hun keuze voor een geschikt en kansrijk programma, is daarom door het NIVEL een inventarisatie gemaakt van beschikbare beweegprogramma's. ${ }^{4,5}$ De vraagstelling die bij deze inventarisatie centraal stond is welke beweegprogramma's er in Nederland beschikbaar zijn en wat de kwaliteit van deze programma's is. Om de 
kwaliteit te beoordelen werden de gevonden beweegprogramma's op een aantal criteria getoetst aan de hand van een nieuw ontwikkeld toetsingsformulier. In dit toetsingsformulier stonden uitvoerbaarheid, theoretische en empirische onderbouwing van het beweegprogramma, alsmede ervaringen uit de praktijk centraal.

Het beoordelen van de kwaliteit van programma's die zich richten op verbetering van leefstijl, waaronder beweegprogramma's, gebeurt op meerdere plaatsen. Sinds 2008 bestaat bijvoorbeeld de Erkenningscommissie van het Centrum Gezond Leven (CGL) die interventies indeelt in de categorieën goed beschreven, theoretisch goed onderbouwd, waarschijnlijk effectief en bewezen effectief. Programma eigenaren moeten hun interventie zelf aanmelden voor beoordeling middels het invullen van een uitgebreid formulier. In de praktijk blijkt dit voor een aantal programma-eigenaren een drempel te zijn, mede gezien het feit dat dit veel tijd kost. Daarbij voldoen nog weinig van de meestal uit de praktijk ontstane programma's aan de eisen van het niveau 'waarschijnlijk effectief' omdat hiervoor een gecontroleerd effectonderzoek nodig is. Doordat bij de beoordeling van het NIVEL net iets andere criteria worden gehanteerd en onderscheid wordt gemaakt in verschillende niveau's van experimentele onderbouwing (pre-, quasi- of true-experimenteel) kan beter gedifferentieerd worden in de grote groep van programma's die goed beschreven zijn maar nog geen gecontroleerd onderzoek hebben kunnen uitvoeren. Daarnaast focust dit overzicht specifiek op beweegprogramma's en hoeven programma-eigenaren alleen bestaand materiaal aan te leveren en geen extra formulier in te vullen.

In dit artikel wordt het verzamelen van de beweegprogramma's, de totstandkoming van het toetsingsformulier en het beoordelen van de programma's beschreven. Er wordt een overzicht gegeven van beschikbare beweegprogramma's in Nederland en tevens wordt de stand van zaken besproken betreffende de uitvoerbaarheid en empirische onderbouwing van deze programma's.

\section{METHODE}

\section{Inventarisatie beweegprogramma's}

Via verschillende kanalen is in 2009 en 2010 gezocht naar beweegprogramma's. Via websites van universiteiten en hogescholen werden contactpersonen benaderd van vakgroepen die zich bezighouden met beweegprogramma's en/of het bevorderen van een gezonde leefstijl. Alle regiocoördinatoren van provinciale sportraden, de hoofden Gezondheidsbevordering (GB) van de GGD, leden van de Nederlandse Vereniging voor Preventie en Gezondheidsbevordering (NVPG) en het NOC*NSF zijn aangeschreven. Programma-eigenaren van programma's die uitgevoerd worden door of bekend zijn bij NISB werden benaderd en op de website en in de nieuwsbrief van het NISB is een oproep voor aanmelding van beweegprogramma's geplaatst. Vooraf genoemde voorwaarden om in het overzicht te worden opgenomen waren dat 'bewegen' in het programma een belangrijk doel of middel was. Tevens diende het programma een contactpersoon en een handboek of protocol te hebben, meer dan drie bijeenkomsten te omvatten en drie keer te zijn uitgevoerd. Aan programma-eigenaren is gevraagd om materiaal zoals handleidingen, stappenplannen, protocollen, onderzoeks- en voortgangsverslagen op te sturen, aan de hand waarvan hun programma werd beoordeeld.

\section{Kernpunten}

- In totaal zijn 72 relevante beweegprogramma's gevonden die zich richten op verandering van beweeggedrag. Hiervan beogen 51 ook de kennis en attitude ten aanzien van gezondheid en bewegen te verbeteren.

- Het merendeel van de programma's heeft als doelgroep 'jeugd' ( $n=42), 20$ programma's richten zich op overgewicht en 14 op mensen met een chronische aandoening.

- Programma's vertonen soms veel overeenkomsten, maar bevinden zich in verschillende stadia van ontwikkeling.

- Het zou goed zijn programma's te bundelen tot enkele goed onderbouwde varianten en die in een gecontroleerd design op effectiviteit te toetsen.

- Van vijf programma's zijn significant positieve effecten op 'meer bewegen' gevonden in een gecontroleerd design. Om de meer en minder effectieve beweegprogramma's van elkaar te kunnen onderscheiden is meer onderzoek nodig. 


\section{Ontwikkeling toetsingsformulier}

Bij de ontwikkeling van het toetsingsformulier is zoveel mogelijk aangesloten bij bestaande instrumenten als de nieuwste Erkenningscriteria 2009-2010 van de Erkenningscommissie Interventies van het Nederlands Jeugdinstituut en het RIVM (Centrum Jeugdgezondheid en centrum Gezond Leven) ${ }^{6}$ en de Preffi2.0 (noot a). ${ }^{7}$ Deze aansluiting is relevant omdat de doelstellingen van het onderhavig NIVEL onderzoek, de Preffi en de Erkenningscommissie overlap vertonen, namelijk het bepalen van de kwaliteit van gezondheidsbevorderende programma's. Het toetsingsformulier is tot stand gekomen in samenspraak met adviseurs van het CGL, twee programma-eigenaren, vertegenwoordigers van het NISB, NOC*NSF en het ministerie van VWS.

Belangrijke items van het toetsingsformulier waren een beschrijving van de werkwijze en de doelen van het beweegprogramma, informatie over de uitvoerbaarheid (overdraagbaarheid), en de theoretische en empirische onderbouwing van het programma. Daarnaast werd gekeken of er een procesevaluatie van het beweegprogramma was gedaan, of er ervaringen uit de praktijk bekend waren, en wat de kosten van het programma waren. Ten slotte is geïnventariseerd in hoeverre het programma aandacht besteedde aan verankering ervan in de toekomst. In dit artikel worden omwille van de lengte alleen de items uitvoerbaarheid, empirische onderbouwing en ervaringen uit de praktijk gepresenteerd omdat deze het meest relevant zijn voor de totaalbeoordeling. Voor meer informatie over de gehele scoringsprocedure en de uitgebreide resultaten wordt verwezen naar Leemrijse et al. ${ }^{4,8}$

\section{Scoring beweegprogramma's}

Aan de hand van de verzamelde documenten werden de programma's gescoord met het toetsingsformulier. Om de objectiviteit en transparantie van dit scoren te waarborgen werden alle programma's door twee onderzoekers (CJL en LO) gescoord. Wanneer verschillend werd gescoord werd middels overleg getracht tot consensus te komen en indien dit niet mogelijk was werd een derde onderzoeker (CV) ingeschakeld. Om te controleren of de verzamelde informatie compleet en goed geïnterpreteerd was, werden de ingevulde toetsingsformulieren vervolgens naar de programma-eigenaren gestuurd met de vraag of het programma zo goed werd weergegeven. Vijftig programma-eigenaren (69\%) stuurden het toetsingsformulier, eventueel voorzien van aanvullingen en/of verbeteringen weer retour naar het NIVEL. De beweegprogramma's waarvan de programma-eigenaar niet reageerde werden wel in het onderzoek meegenomen en hierbij werd de score van de onderzoekers aangehouden.

\section{Uitvoerbaarheid}

Uitvoerbaarheid werd gescoord door te inventariseren welke ondersteuning vanuit de organisatie beschikbaar is voor het lokaal uitvoeren van het beweegprogramma en te beoordelen of de beschikbare materialen (handleiding/ protocol / stappenplan / website) voldoende informatie bieden om lokaal met het programma van start te kunnen gaan.

De volgende criteria (1.1 tot en met 2.5) werden daarbij met het toetsingsformulier gescoord:

Ondersteuning vanuit de organisatie:

Mogelijkheid om expertise (uitvoerende professionals) in te huren

Helpdesk of contactpersoon is beschikbaar

Deskundigheidbevordering zoals cursus / training; workshop; coaching

Wanneer het beweegprogramma aan twee of meer criteria voldeed is een + gescoord voor item 'ondersteuning'.

Welke informatie bieden de handleiding/ het protocol / stappenplan / website:

Randvoorwaarden staan helder beschreven (wie, wat, waar, hoeveel (menskracht, materiaal en financiën)), welke deskundigheid is nodig, functieprofielen, welke samenwerkingspartners, wat zijn eventuele knelpunten voor aanpassing aan de lokale situatie.

Doelgroep wordt nauwkeurig omschreven, relevante kenmerken van de doelgroep zijn in kaart gebracht

Doelen zijn omschreven, waarbij indien van toepassing onderscheid wordt gemaakt in primaire doelen

(bijvoorbeeld meer bewegen) en verder gelegen doelen (bijvoorbeeld gezondheidswinst)

Methodiek om de interventie op te zetten (benodigde handelingen, materialen) staat in detail uitgeschreven De handleiding is afgestemd op de beoogde uitvoerders (ten aanzien van de inhoud van de activiteiten: volgorde, duur, frequentie en intensiteit)

Bij het voldoen aan vier criteria kreeg het programma een + , wanneer aan alle 5 subcriteria werd voldaan een ++ voor het item 'informatie in de handleiding'. In totaal kon voor uitvoerbaarheid maximaal +++ 
worden gescoord door de scores op item 1 (ondersteuning) en item 2 (informatie handleiding) samen te nemen.

\section{Empirische onderbouwing}

Voor wat betreft de empirische onderbouwing is gekeken of er onderzoek was gedaan naar het effect van de interventie op de uitkomstmaat 'meer bewegen' en zo ja, wat daarvan de resultaten waren (noot b). Het beweegprogramma kon daarbij de volgende score behalen op grond van het gekozen design:

Geen enkel evaluatieonderzoek uitgevoerd $\rightarrow-$

Pre-experimenteel onderzoek met alleen een nameting van de effecten bij de interventie groep (deelnemers en/of betrokken professionals) $\rightarrow+/-$

Pre-experimenteel onderzoek met alleen een nameting van de effecten bij de interventie groep en bij een controlegroep die de te onderzoeken interventie niet kreeg $\rightarrow+$

Pre-experimenteel onderzoek met een voor- en nameting van de effecten bij alleen de interventie groep $\rightarrow$ $+$

Quasi-experimenteel onderzoek waarin de effecten van de interventie bij twee niet willekeurig samengestelde groepen (interventie- en controlegroep) worden vergeleken op een voor- en nameting $\rightarrow++$

True-experimenteel onderzoek waarin de effecten van de interventie bij twee willekeurig samengestelde groepen (interventie- en controlegroep) worden vergeleken op een voor- en nameting $\rightarrow++$

Indien het beweegprogramma een + of ++ scoorde op voorgaande vraag werd het effect beoordeeld, waarbij een significant positief effect ++ scoorde, een positief (niet significant) effect een + en geen effect +/-. In totaal kon voor empirische onderbouwing maximaal ++++ worden gescoord.

\section{Ervaringen uit de praktijk}

Om de ervaringen uit de praktijk in kaart te brengen is gekeken naar ervaringen van uitvoerders en deelnemers, participatiegraad van de deelnemers en naar het aantal locaties waarop het programma reeds is uitgevoerd. Van deze items wordt, indien zij getalsmatig werden weergegeven, verondersteld dat zij iets zeggen over het kansrijk zijn van een programma om mensen in beweging te krijgen. Een programma kreeg een + wanneer het meer dan $60 \%$ van de professionals de uitvoerbaarheid van de interventie positief beoordeelde, meer dan $60 \%$ van de deelnemers de interventie positief beoordeelde, meer dan $>60 \%$ van de deelnemers alle bijeenkomsten aanwezig was en wanneer het programma op meer dan drie verschillende locaties is uitgevoerd. Doordat per item werd gescoord, kon een programma maximaal ++++ scoren voor ervaringen uit de praktijk.

\section{Totaalbeoordeling wat betreft kansrijkheid om mensen meer te laten bewegen}

Bij het bepalen van de totaalbeoordeling en de indeling in categorieën werden empirische onderbouwing (effectiviteit), uitvoerbaarheid en ervaringen in de praktijk meegenomen (tabel 3). Effectiviteit was daarbij het onderscheidend criterium, terwijl goede uitvoerbaarheid (minimaal ++ ) als voorwaarde werd gesteld voor opname in de eerste drie categorieën.

In categorie I, zijn de programma's opgenomen waarvan in een sterk onderzoeksdesign $(++)$ was aangetoond dat zij een significant effect op 'meer bewegen' hebben $(++++)$. In categorie II werden de programma's opgenomen waarvoor sterke aanwijzigen voorhanden waren dat het programma een effect op 'meer bewegen' heeft $(+++)$. Deze programma's waren middels een minder sterk design onderzocht $(+)$ óf onderzocht in een sterk design waarbij positieve resultaten op 'meer bewegen' werden gevonden die niet statistisch significant waren.

Categorie III werd gevormd door programma's waarvoor enige aanwijzigen waren voor een positief effect, maar waarbij het design pre-experimenteel was en de gevonden positieve effecten op 'meer bewegen' niet statistisch significant waren. Daarnaast konden programma's waarvoor geen effectonderzoek is verricht in categorie III terecht komen, indien zij zeer positief scoorden op ervaringen uit de praktijk (minimaal +++ ). Het kan namelijk zo zijn dat nog geen onderzoek is uitgevoerd in verband met gebrek aan middelen. Een programma dat goed uitvoerbaar is en waarmee gekwantificeerde positieve ervaringen in de praktijk zijn vastgesteld, wordt als kansrijk genoeg gezien om in categorie III geplaatst te worden.

De programma's die niet in één van bovenstaande categorieën vielen werden samengevoegd tot een vierde categorie of restgroep. 


\section{RESULTATEN}

\section{Gevonden beweegprogramma's}

In totaal zijn 72 relevante beweegprogramma's gevonden waaruit gemeenten kunnen kiezen. Een overzicht van alle 72 programma's met de belangrijkste kenmerken is op te vragen bij de auteurs ${ }^{8}$. Elf van deze programma's worden aangemerkt als 'bewegingsstimulerend'. Deze programma's bestaan uit drie of meer bijeenkomsten en hebben 'meer bewegen' als expliciet doel, maar bewegen niet noodzakelijk standaard drie of meer keer met de doelgroep. Deze programma's proberen de doelgroep te stimuleren tot meer bewegen door bijvoorbeeld kennisoverdracht, motivatiegesprekken, beweegdagboekjes of stappentellers. Bij de overige 61 programma's wordt drie of meer keer echt bewogen. De beweegprogramma's zijn er allen op gericht om beweeggedrag te veranderen en 51 programma's beogen tevens de kennis en attitude ten aanzien van gezondheid en bewegen te verbeteren. Ruim de helft van de programma's $(n=37)$ heeft als (sub)doel randvoorwaarden te creëren voor bewegen in de omgeving en ervoor te zorgen dat 'bewegen' wordt ingebed in het beleid en vijftien programma's zijn ook gericht op het opleiden van mensen (trainers, begeleiders).

Het merendeel van de programma's heeft als specifieke doelgroep 'jeugd' $(n=42)$, twintig programma's 'mensen met overgewicht' en veertien programma's zijn bedoeld voor mensen met een chronische aandoening. Achttien programma's richten zich op meerdere doelgroepen. De meeste programma's worden uitgevoerd in de wijk $(n=45)$ binnen school $(n=37)$ en binnen de sport $(n=30)$.

\section{Uitvoerbaarheid}

De uitvoerbaarheid van de beweegprogramma's is beoordeeld op basis van de ondersteuning die de programma-eigenaar een potentiële gebruiker kan bieden. Van het grootste deel van de beweegprogramma's $(n=63)$ is de uitvoerbaarheid goed of zeer goed (Tabel 1). Van enkele beweegprogramma's is weinig informatie beschikbaar gesteld omdat het beleid van het programma is om alleen handleidingen uit te reiken aan deelnemers en/of handleidingen op maat te maken.

\section{[TABEL 1]}

\section{Empirische onderbouwing}

Bij 33 van de 72 beweegprogramma's is geen enkele effectmeting op het terrein van 'meer bewegen' gedaan terwijl bij twaalf programma's alleen een nameting is gedaan onder de deelnemers. Bij zeventien beweegprogramma's werd een voor- en nameting uitgevoerd bij de deelnemers, terwijl negen programma's zijn onderzocht door middel van een voor- en nameting bij deelnemers en een controlegroep. Behalve dat de kwaliteit van het onderzoek erg verschilt tussen de programma's, bestaat er ook een grote variëteit in de methodiek om de effectiviteit op het beweeggedrag te bepalen. Zo wordt er onder andere gebruik gemaakt van verschillende soorten vragenlijsten, interviews (telefonisch of op locatie) en stappentellers.

Van de 26 beweegprogramma's met een sterk design is het gevonden effect geclassificeerd: bij achttien beweegprogramma's werden positieve effecten gevonden op het bewegen en bij twaalf van deze achttien programma's zijn de effecten statistisch significant. Bij vijf programma's werden significant positieve effecten gevonden in een gecontroleerd design (Tabel 2).

\section{[TABEL 2]}

\section{Ervaringen uit de praktijk}

De meningen van de professionals en deelnemers, de compliance van de deelnemers en het aantal locaties waar het programma reeds is uitgevoerd zijn meegenomen in de beoordeling van het programma. Het getalsmatig weergeven van ervaringen en compliance komt echter niet vaak voor. Van dertien beweegprogramma's wordt in het beschikbare materiaal geen enkele getalsmatige informatie over meningen van professionals of deelnemers, compliance of locaties gevonden, terwijl voor vier beweegprogramma's al deze vier items positief kunnen worden gescoord. Negentien programma's scoren op drie van de vier onderdelen positief.

Totaalbeoordeling wat betreft kansrijkheid om mensen meer te laten bewegen

Bij het bepalen van de totaalbeoordeling worden de items effectiviteit, uitvoerbaarheid en ervaringen uit de praktijk meegenomen. In de hoogste categorie, categorie I, zijn vijf programma's, 'COACH-methode', 
Fiets-Fit, 'JUMP-in', 'Revalidatie, Sport en Bewegen' en 'Start to Run' opgenomen (Tabel 3). Deze programma's kunnen op dit moment als de meest kansrijke programma's worden beschouwd om mensen meer in beweging te krijgen.

Deze vijf 'best practices' richten zich op verschillende doelgroepen. De programma's hebben, met uitzondering van Start to Run en Fiets-Fit wat beide sportprogramma's voor gezonde volwassenen zijn, weinig gemeenschappelijke kenmerken (Box 1).

[Box 1]

In de daarop volgende categorie II vallen acht programma's: 'Alle leerlingen Actief!', 'Be Interactive', 'Bewegen valt goed', 'De beweegkuur', 'Gezond in de buurt in beweging', 'Okido!', 'SMALL', 'Scoren voor Gezondheid' en 'Start to Run'. Categorie III wordt gevormd door twaalf programma's. Voor drie van deze twaalf programma's bestaan aanwijzingen dat ze een positief effect hebben op 'meer bewegen' ('Denken en Doen', 'GALM', 'IRun2BFit'), maar is dit nog niet in een voldoende sterk onderzoeksdesign aangetoond. Van de overige vijftien programma's ('ACTOR', 'Beachvolleybal', 'B-Fit', 'Bewegen als warming up voor re-integratie', 'Bewegen op Recept', 'Cool Moves Volley', 'De klas beweegt!', 'Fithockey', 'In Balans', 'Judo op school', 'Kies voor Hart en Sport', 'Masters trendweken', 'SCALA', 'Yalp, beweegprogramma voor ouderen' en 'ZORG-methode') is geen onderzoek naar bewegingseffecten gedaan of is alleen een nameting verricht, maar deze programma's scoren goed op uitvoerbaarheid en kunnen goede ervaringen uit de praktijk aangeven.

In categorie IV zijn 41 beweegprogramma's opgenomen. Bij 29 van deze beweegprogramma's is nog geen enkele effectmeting ten aanzien van 'meer bewegen' uitgevoerd. Bij vier van deze programma's is alleen een nameting verricht onder de deelnemers (Communities in Beweging, Club2Move, Club Fit 4 Utrecht, Van klacht naar kracht) en van twee programma's is het onderzoeksdesign niet te beoordelen (Ga voor gezond, groep 6 on the move). Bij zes van de 41 programma's is wel een effectonderzoek gedaan, maar zijn geen positieve effecten gevonden (DoiT, Lekker Fit!, Masters Trendweken, Moving cultures, Realfit). Van de programma's uit categorie IV is momenteel nog weinig te zeggen van de mate waarin ze kansrijk zijn om mensen aan het bewegen te krijgen.

\section{[TABEL 3]}

\section{DISCUSSIE}

Binnen Nederland zijn veel ontwikkelingen gaande om mensen meer te laten bewegen en er is brede aandacht voor het probleem van inactiviteit onder de bevolking. In dit onderzoek zijn 72 programma's gevonden die gemeenten kunnen uitzetten om meer bewegen in de bevolking te stimuleren. Onderhavig onderzoek biedt inzicht in de kwaliteit van beweegprogramma's die in Nederland voor verschillende doelgroepen beschikbaar zijn. De kwaliteit en de mate van onderbouwing van de programma's lopen sterk uiteen en er kan geen algemene conclusie worden getrokken ten aanzien van het soort programma dat het meest kansrijk is om mensen meer te laten bewegen. De vijf best beoordeelde programma's vertonen onderling sterke verschillen, zowel wat doelgroep als wat methode betreft.

Aan de hand van de informatie uit dit onderzoek heeft het NISB de beweegprogramma's in 2010 in een papieren overzicht gezet en verspreid onder gemeenten. Dit overzicht is tevens gepresenteerd op hun website (www.nisb.nl/kansrijke-beweeginterventies/overzicht-interventies.html) en zal in 2011 vernieuwd worden. Ook is een deel van de beweegprogramma's in de Handreiking Gezonde Gemeente van het Loket Gezond Leven gepresenteerd. Hoewel het wellicht verwarrend is voor gemeenten dat er vanuit verschillende bronnen (CGL, NIVEL/NISB) met ieder een eigen systematiek informatie wordt aangeboden, is het relevant de beweegprogramma's op verschillende manieren bij gemeenten onder de aandacht te blijven brengen. Uit onderzoek van TNO bleek het overzicht bij 94\% van de professionals van provinciale sportraden, gemeenten en GGDs bekend te zijn en $92 \%$ van hen vond het overzicht zeer nuttig. ${ }^{9}$ Zoals gesteld in de inleiding bevat het hier gepresenteerde overzicht tevens beweegprogramma's die door programma-eigenaren (nog) niet zijn aangemeld bij het CGL en wordt onderscheid gemaakt in verschillende typen van wetenschappelijke onderbouwing.

Beweegprogramma's die nog niet theoretisch of met gecontroleerd onderzoek zijn onderbouwd maar in de praktijk goed uitvoerbaar blijken, kunnen in potentie wel effectief zijn in het stimuleren van meer bewegen en dienen daarom actief onder de aandacht van de gemeenten worden gebracht. 


\section{Een veelheid aan interventies}

Enerzijds is het een goede zaak dat veel programma's beschikbaar zijn om mensen aan het bewegen te krijgen en te houden, gezien de risico's die inactiviteit met zich mee brengt. Anderzijds lijkt er ook veel energie te worden besteed aan het ontwikkelen van telkens net iets andere programma's die in principe vergelijkbare doelen nastreven. Het grootste deel van de beweegprogramma's richt zich op de jeugd. Onder deze programma's bevinden zich naast specifieke sportprogramma's veel programma's die op school worden uitgevoerd, veelal bestaande uit lespakketten met informatie over gezond eten en meer bewegen. De programma's vertonen naast enkele inhoudelijke verschillen ook veel overeenkomsten, maar bevinden zich in verschillende stadia van ontwikkeling. Het zou wellicht efficiënter zijn deze programma's te bundelen tot één of enkele goed onderbouwde varianten en die in een goed gecontroleerd design op effectiviteit te toetsen.

\section{Noodzaak verdere onderbouwing}

Algemeen kan worden gesteld dat er nog veel aandacht nodig is voor het onderbouwen van de bestaande beweegprogramma's om de meer en minder effectieve programma's van elkaar te kunnen onderscheiden. De hier gepresenteerde indeling van beweegprogramma's in meer en minder kansrijke categorieën is dan ook een tijdelijke. Doordat veel programma's nog in ontwikkeling zijn is het nog niet altijd mogelijk goed in te schatten hoe kansrijk een programma is in het bevorderen van meer lichaamsbeweging. Van nog weinig beweegprogramma's is onderzoek naar de effecten uitgevoerd. De reden hiervoor is waarschijnlijk dat effectonderzoek naar beweegprogramma's lastig is uit te voeren en kostbaar is. Programma-eigenaren hebben vaak onvoldoende specifieke kennis om zelf onderzoek te doen en onvoldoende budget om het uit te besteden. Maar ook wanneer er wel effectonderzoek is uitgevoerd, is het vaststellen van positieve effecten nog niet altijd vanzelfsprekend. Beweeggedrag is moeilijk te beïnvloeden omdat meer bewegen echt een verandering in leefstijl vraagt. Daarbij is beweeggedrag moeilijk betrouwbaar te meten. Naast aandacht voor goed gecontroleerd effectonderzoek zou er dus aandacht moeten zijn voor de ontwikkeling en keuze van goede meetinstrumenten. Bij voorkeur worden bij de evaluatie van beweegprogramma's vergelijkbare meetinstrumenten gebruikt zodat de effecten van programma's ook onderling kunnen worden vergeleken. Wanneer van de programma's de effecten bekend zijn is pas goed mogelijk de meest kansrijke programma's te onderscheiden en inzicht te verkrijgen in de kosteneffectiviteit. In de toekomst zouden met name de meest kansrijke en meest kosteneffectieve beweegprogramma's moeten worden ingezet om lichaamsbeweging in de bevolking te bevorderen. Overzichten zoals deze studie en het overzicht vanuit het $\mathrm{CGL}^{10}$ illustreren de noodzaak van meer aandacht voor onderbouwing van beweegprogramma's en stimuleren hopelijk de verdere ontwikkeling van onderzoek hiernaar.

\section{NOTEN}

Preffi staat voor Preventie Effectmanagement Instrument. Het instrument is door het NIGZ ontwikkeld in samenwerking met GVO-praktijkmedewerkers (Gezondheidsvoorlichting en -opvoeding), preventiedeskundigen en wetenschappelijk onderzoekers en heeft tot doel de effectiviteit van gezondheidsbevorderende projecten te vergroten, door het ondersteunen van een systematische werkwijze.

Er werd hierbij geen onderscheid gemaakt tussen meer bewegen puur door het deelnemen aan het programma op zich of een additioneel effect op meer bewegen naast deelname aan het programma.

\section{LITERATUUR}

1. Proper $\mathrm{KI}$, Zaanen $\mathrm{S}$ van. Relatie tussen sedentair gedrag en (on)gezondheid: een literatuurstudie. Leiden: TNO Kwaliteit van Leven, 2008, 89-112.

2. VWS. Samen voor sport - Uitvoeringsprogramma 2006-2010 van de kabinetsnota "Tijd voor sport bewegen, meedoen en presteren". Den Haag: ministerie van VWS, 2006.

3. Inspectie voor de Gezondheidszorg. Staat van de Gezondheidszorg 2010. Den Haag: Inspectie voor de Gezondheidszorg, 2010.

4. Leemrijse CJ, Ooms L, Veenhof C. Evaluatie van kansrijke beweegprogramma's om lichaamsbeweging in de bevolking te stimuleren. Utrecht: NIVEL, 2010.

5. Ooms $L$, Veenhof $C$. Evaluatie van kansrijke interventies om lichaamsbeweging in de bevolking te bevorderen. Utrecht: NIVEL, 2008.

6. Yperen T van, Bommel M van. Erkenning interventies: criteria 2009-2010 Erkenningscommissie 
Leemrijse, C.J., Ooms, L., Veenhof, C. Evaluatie van kansrijke beweegprogramma's om lichaamsbeweging-in de Nederlandse bevolking te bevorderen. TSG: Tijdschrift voor Gezondheidswetenschappen: 2011, 89(7), 372. 379

(Jeugd)Interventies. Bilthoven: NJi/RIVM, 2009.

7. Peters L, Molleman G, Hommels L et al. Toelichting Preffi 2.0. Woerden: NIGZ, 2003.

8. Leemrijse CJ, Ooms L, Veenhof C. Evaluatie van kansrijke programma's om lichaamsbeweging in de bevolking te bevorderen. Fase 3. Utrecht: NIVEL, 2011

9. Stubbe $\mathrm{JH}$, Chorus AMJ. Monitor onder professionals in het werkveld van sport en bewegen, Leiden, TNO Kwaliteit van Leven, 2010.

10. Dale D van, Dijk S van, Lanting L et al. Meer zicht op kwaliteit en effectiviteit van (leefstijl)interventies: Erkenningscommissie interventies. Tijdschr Gezondheidswet 2010;88:236-40. 
Leemrijse, C.J., Ooms, L., Veenhof, C. Evaluatie van kansrijke beweegprogramma's om lichaamsbeweging-in de Nederlandse bevolking te bevorderen. TSG: Tijdschrift voor Gezondheidswetenschappen: 2011, 89(7), 372.

\section{TABELLEN EN BOX}

\section{Tabel 1}

Tabel 1 Totaalscore uitvoerbaarheid per bewegingsprogramma

\section{Mate van uitvoerbaarheid}

Uitvoerbaarheid onvoldoend $\mathrm{e}^{1}(\mathrm{o})$

Gezond Gewicht

Familie Lekkerbek op bezoek bij Korein

Vet lekker..lekker fit

Uitvoerbaarheid redelijk $\mathrm{k}^{2}(+)$

Beweeg je Beter

Big!Move

Bewegen doe je zol

Club2 Move

Ga voor Gezond

Judo op school

Zo kan het ook

Uitvoerbaarheid goed ${ }^{2}(++)$

ACTOR

Be Interactive

Be Interactive

Bewegen als Warming up voor re-integratie

ClubExtra

COACHmethode

De klas
DOiT

Gezond in de buurt in beweging

Gezonde Leefstijl

Go! Fit met power

Groep 6 on the move

Ketenaanpak Actieve Leefstij|

KNVB45+

Okido!

RealFit

SCALA

SMALL ${ }^{3}$

Sportmix

School en Sport

Schooljudo

Start to Run

Uitvoerbaarheid zeer goed ${ }^{2}(+++)$

Alle leerlingen actief

Basisscholen zaalvoetbalcompetitie

Beachvolleybal

Bewegen op recept

Bewegen valt goed

B-Fit

Cool Moves Volley

Club Fit 4 Utrecht

Communities in Beweging

De beweegkuur

Denken en Doen

Evenwich

Fiets Fit

Fithocke

GALM

In Balans

Irun2BFit

JUMP-in

Kids for Fit

Kids in Balance

Kies voor Hart en Sport

KorfbalFit

Lekker fit!

Liever Bewegen Dan Moe

Masters Trendweken

Moving cultures

Revalidatie, Sport en Bewegen

Scoren voor Gezondheid

Schoolgolf

schoolgolf

scoOLsp

Special heroes

Sportieve schoo

Trappen Scoort

Van klacht naar krach

vet Cool Gezond

Via Vierdaa

WhoZnext

Yalp ouderen in

${ }^{1}$ of niet te toetsen aan de hand van het beschikbare materiaal.

${ }^{2}$ Voor zover kan worden getoetst aan de hand van het beschikbare materiaal.

${ }^{3}$ SMALL maakt gebruik van het handboek van GALM, dat hier in de

beoordeling is meegenomen. 
Leemrijse, C.J., Ooms, L., Veenhof, C. Evaluatie van kansrijke beweegprogramma's om lichaamsbeweging-in de Nederlandse bevolking te bevorderen. TSG: Tijdschrift voor Gezondheidswetenschappen: 2011, 89(7), 372. 379

\section{Tabel 2}

Tabel 2 Totaalscore effectiviteit voor programma's die minimaal met een voor-en nameting bij de deelnemers zijn onderzocht

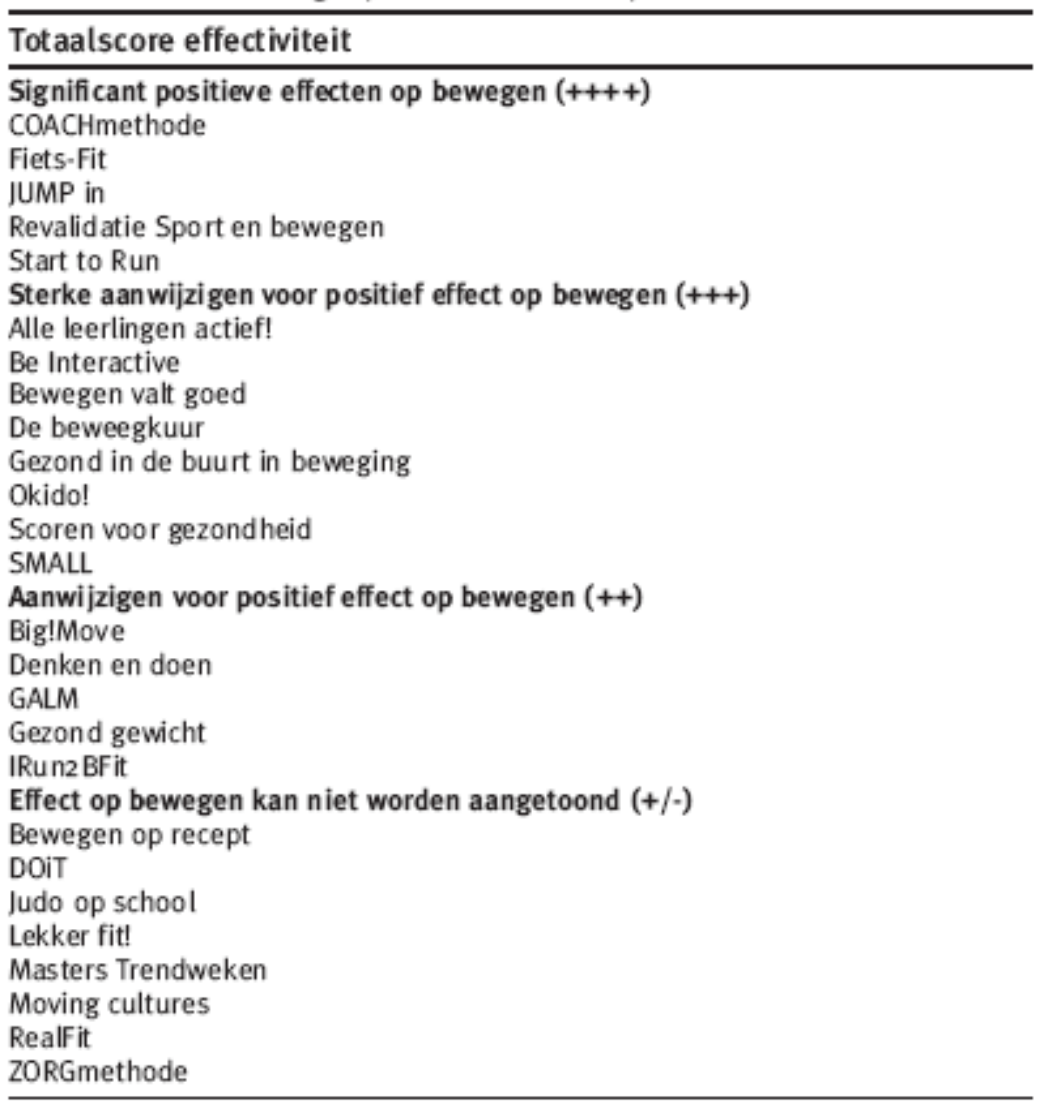


Leemrijse, C.J., Ooms, L., Veenhof, C. Evaluatie van kansrijke beweegprogramma's om lichaamsbeweging in de Nederlandse bevolking te bevorderen. TSG: Tijdschrift voor Gezondheidswetenschappen: 2011, 89(7), 372. 379

\section{Box 1}

Box 1. De vijf beweegprogramma's uit categorie I

De COACH methode verhoogt de lichamelijke activiteit van mensen met bewegingsarmoede, door activiteiten in het dagelijks leven zoals wandelen, fietsen en traplopen te stimuleren. Het stimuleren van lichamelijke activiteiten in het dagelijks leven wordt ondersteund door "Exercise Counseling" in kleine groepjes of individueel en er wordt gebruik gemaakt van een stappenteller. Specifiek getrainde zorgverleners voeren de gesprekken. De kwaliteit van leven van deelnemers verbetert, de deelnemers zijn fitter en bewegen meer.

Fiets-Fit ondersteunt beginnende fietsers gedurende 6 weken bij het verbeteren van de conditie en het aanleren van de basistechnieken. De doelgroep van Start met Fiets-Fit is breed, variërend van gezondheidsfietsers (beginnende, veelal te weinig bewegende fietsers), recreatieve fietsers, sportieve fietsers tot mountainbikers. Start met Fiets-Fit kan ook binnen bedrijven worden uitgevoerd in het kader van Bedrijfssport. Na 6 maanden is het percentage deelnemers dat voldoet aan de NNGB significant sterker gestegen dan het percentage personen uit de controlegroep.

JUMP-in is een mix van activiteiten (zoals schoolsport, oudervoorlichting, monitoren van motorische vaardigheden, etc.) met als doel kinderen in de basisschoolleeftijd meer te laten bewegen zodat zij de Nederlandse Norm Gezond Bewegen halen. Voor alle kinderen die (nog) niet sporten wordt er een passend bewegingsaanbod gecreëerd, dat via de school zelf wordt aangeboden. Onder schooltijd én na school. Na 1 jaar JUMP-in haalden de kinderen van groep 8 van de interventiescholen significant vaker de NNGB dan de kinderen van groep 8 van de controle scholen

Revalidatie, Sport en bewegen stimuleert sportdeelname en een actieve leefstijl voor revalidanten door binnen een revalidatiecentrum of ziekenhuis een doorverwijzingsystematiek op te zetten die ervoor zorgt dat alle revalidanten/patiënten worden geïnformeerd en gestimuleerd om (meer) aan sport en bewegen te doen. Zowel tijdens als na de revalidatie/behandeling wordt door een sport- en beweegadviseur aandacht besteed aan (het belang van) sport en bewegen, en aan de mogelijkheden die revalidanten hebben om te sporten en bewegen binnen en buiten het revalidatiecentrum/ziekenhuis. Negen weken en een jaar na afloop van het programma sporten de ex-deelnemers nog steeds meer dan degenen die niet aan het programma hebben deelgenomen.

Start to Run biedt beginnende deelnemers gedurende 6 weken één maal per week training van een professionele coach, online adviezen, hu iswerkoefeningen en trainingsschema's om hiernaast zelf tweemaal per week actief te worden. Er worden theorie-items tijdens de lessen aangeboden, bijvoorbeeld over goede schoenen en voeding. Na 6 maanden is het percentage deelnemers dat voldoet aan de Fitnorm en Combinorm significant sterker gestegen dan het percentage personen uit de controlegroep. 
Leemrijse, C.J., Ooms, L., Veenhof, C. Evaluatie van kansrijke beweegprogramma's om lichaamsbeweging-in de Nederlandse bevolking te bevorderen. TSG: Tijdschrift voor Gezondheidswetenschappen: 2011, 89(7), 372. 379

\section{Tabel 3}

Tabel 3 Totaalbeoordeling beweegprogramma's in categorieën

Totaalbeoordeling per categorie

\section{Categorie I \\ COACH methode}

JUMP-in

Revalidatie, Sport en Bewegen

Start to Run

Fiets-Fit

Alle leerlingen Actief

Be Interactive

Bewegen valt goed!

De beweegkuur

Gezond in de buurt in beweging

Okido!

SMALL

Scoren voor Gezondheid

Categorie III

ACTOR

Beachvolleybal

B-Fit ${ }^{2}$

Bewegen op Recept $\mathrm{t}^{3}$

Bewegen als waming up voor re-integratie

Cool Moves Volley (CMV)

De klas beweegt! $!^{2}$

Denken en Doen

Fithockey ${ }^{\mathrm{D}}$

GALM

In Balans ${ }^{2}$

IRun2BFit

Judo op school ${ }^{2}$

Kies vo or Hart en Sport

Masters Trendweke

SCALA ${ }^{2}$

Yalp, beweegprogramma voor ouderen ${ }^{2}$

ZORGmethode $\mathrm{e}^{2}$

Categorie IV

Basisscholen zaalvoetbalcompetitie $^{2}$

Beweeg je Beter ${ }^{2}$

Bewegen doe je zo! ${ }^{2}$

B-Slim kids ${ }^{2}$

ClubExtra $^{2}$

Club2 2 Move $^{3}$

Club Fit 4 Utrecht

Communities in Beweging (CiB) ${ }^{3}$

De familie Lekkerbek op bezoek

DOiT 5

Evenwicht ${ }^{2}$

Ga voor Gezond! ${ }^{4}$

Gezonde Leefstijl ${ }^{2}$

Gezond gewicht ${ }^{6}$

Go! Fit met power

Groep 6 on the move 4

Ketenaanpak Actieve Leefstijl ${ }^{2}$

Kids for Fit ${ }^{2}$

Kids in Balance ${ }^{2}$

KNVB $45^{2}{ }^{2}$

KorfbalFit ${ }^{2}$

Lekker fit! ${ }^{5}$

Liever Bewegen Dan Moe

Moving cultures 5

Realfit ${ }^{5}$

sCOOLsport

School en Sport

Schoolgolf

Schooljudo

Slimkids ${ }^{2}$

Special Heroes ${ }^{2}$

Sportieve school ${ }^{2}$

SportMix ${ }^{2}$

Trappen Scoort ${ }^{2}$

Van klacht naar kracht ${ }^{3}$

Vet Cool Gezond ${ }^{2}$

Vet lekker...lekker fit ${ }^{2}$

Via Vierdaagse ${ }^{2}$

WhoZnext ${ }^{2}$

Zo kan het ook! ${ }^{2}$

" $0 . b . v$, een goede uitvoerbaarheid (minstens ++) en goede ervaringen uit de praktijk (minstens +++) zijn deze programma's bij de achtervolgers op genomen, terwijl er geen effectmeting is gedaan, alleen een nameting is uitgevoerd, of er in een effectmeting geen positieve resultaten werden gevonden.

2 Geen enkele effectmeting op de uitkomstmaat 'meer bewegen'.

${ }^{3}$ Alleen een nameting onder de deelnemers.

${ }_{5}^{4}$ Design niet te achterhalen.

${ }^{5}$ wel onderzoek gedaan maar geen positieve effecten op de uitkomstmaat 'meer

bewegen' gevonden.

${ }^{6} \mathrm{Er}$ zijn voor dit programma's wel aanwijzingen voor positieve effecten gevonden,

maar de uitvoerbaarheid scoorde niet vold oende om het in categorie III op te nemen. 